\title{
Çocukluk çağı tiroid nodüllerine yaklaşım
}

\section{Approach to thyroid nodules in childhood}

\author{
Sevinç ODABAŞI GÜNEŞ ${ }^{1 a}$, Ayça TÖREL ERGÜR'
}

'Kırıkkale Üniversitesi Tıp Fakültesi, Çocuk Endokrinoloji Bilim Dalı, Kırıkkale, TÜRKIYE

\section{öz}

Çocuklarda tiroid nodül gelişiminde genetik ve çevresel bir çok faktör rol oynamaktadır. Çocukluk çağında palpe edilebilen tiroid nodül sıklığı \%2 olarak bildirilmektedir. Günümüzde ultrasonografinin daha yaygın olarak kullanılması nedeniyle bu oranın \%5' e kadar çıktığını gösteren çalışmalar mevcuttur. Çocukluk çağında tespit edilen tiroid nodüllerinin büyük bir kısmının benign karakterde olmasına karşın erişkin yaş grubu ile kıyaslandığında çocuklarda tiroid nodül malignansi insidansının daha yüksek olduğu bildirilmektedir. Çocukluk çağı tiroid nodüllü olgularda tanı anında uzak metastaz yapma riski ve tedavi sonrası rekürrens riskinin erişkin yaş grubuna göre daha yüksek olması nedeniyle de bu olguların erken tanı ve tedavisi hayati önem arz etmektedir. Günümüzde radyolojik görüntüleme tekniklerinin kullanımının artması, immünohistokimyasal ve moleküler tanı yöntemlerinin gelişmesi tiroid nodüllü olguların erken tanı almasına ve uygun tedavi yönetiminin belirlenmesine yardımcı olmaktadır. Bu yazıda çocukluk çağında tiroid nodül gelişimine yol açan nedenlerle ve malignansiyi telkin eden bulgular irdelenerek güncel tanı ve takip yaklaşımları literatür eşliğinde sunulmuştur.

Anahtar Kelimeler: Çocukluk çağı, tiroid nodül, güncel yaklaşım

\section{ABSTRACT}

Many genetic and environmental factors play role in the etiology of thyroid nodules in the childhood. The incidence of palpable thyroid nodules in childhood is known as $2 \%$. There are studies indicating that this incidence is increased to $5 \%$ since thyroid ultrasonography is used more commonly. Although most of the thyroid nodules are benign in the children, incidence of malignancy of thyroid nodules in childhood is quite higher than adults. The early diagnosis and treatment of thyroid nodules in childhood is of vital importance since risk of distant metastasis at the time of diagnosis and recurrence rate after treatment is much higher than adult age group. Nowadays, the higher utilization rates of radiological imaging, immunohistochemical and molecular diagnostic techniques help the early diagnosis of the cases and selection of proper therapeutic interventions. In this paper, predisposal factors and risk factors for malignancy of thyroid nodules in childhood is discussed, treatment and follow-up approach is reviewed with the literature.

Keywords: Childhood, thyroid nodules, current approach

Corresponding Author a: Dr. Sevinç Odabaşı Güneş. Kırıkkale Üniversitesi Tıp Fakültesi, Çocuk Endokrinoloji Bilim Dalı, Kırıkkale, TURKEY Phone: +90 4444071-5223

e-mail: sevincodabasi@yahoo.com

Received 01.08.2016, accepted 29.09.2016

Doi: $10.18663 /$ tjcl.320046 


\section{Giriş}

Çocukluk çağında palpe edilebilen tiroid nodül sıklığı yaklaşık olarak \%2 civarındadır [1]. Saptanan tiroid nodüllerinin ise yaklaşık olarak \%25'i malign özellik göstermektedir ve bu oran erişkin yaş grubu ile kıyaslandığında (\%5) çok yüksektir [2-4]. Ayrıca erişkin yaş grubundan farklı olarak çocukluk çağında tanı anında lenf nodu ya da uzak metastaz yapma olasılığının yüksek olması ve yüksek nüks oranları nedenleriyle tiroid kanserleri daha agresif bir seyir izlemektedir [2]. Bu nedenle çocukluk çağında tiroid nodüllü olguların erken dönemde tespit edilerek malign özellik gösteren olguların tanımlanması ve detaylı incelenmesi hayati bu açıdan önem arz etmektedir.

\section{Epidemiyoloji ve Predispozan Faktörler}

Yapılan çalışmalarda erişkin çağı tiroid nodül prevalansı palpasyonla \%2-6, ultrasonografi (USG) ile \%19-35, postmortem çalışmalarda \%8-65 arasında olduğu bildirilmiştir [5]. Çocukluk çağına ait bilgiler ise oldukça kısıtlıdır.1975 yılında Amerika Birleşik Devletleri'nde yapılan büyük bir çalışmada palpasyon ile çocukluk çağında saptanan tiroid nodül sıklığının \%1,79 olduğu bildirilmiştir [1]. Son yıllarda USG'nin daha sık kullanılması nedeniyle bu oranın \%0,2-5,1 arasında değiştiği bildirilmektedir [2].

Çocukluk çağı endokrinolojik malignansileri oldukça nadir olmakla birlikte bu olguların büyük bir kısmını tiroid kanserli vakalar oluşturmaktadır [6]. Kız/erkek oranı 15 yaş öncesinde 3/1 iken 15 yaş sonrasında 6/1' e yükselmektedir $[5,6]$. "Survelliance, Epidemiology and End Results (SEER), National Institue of Healtyh" nin 1973- 2006 yılları arasındaki verilerine göre tiroid kanserli olgu insidansı 5-9 yaş arasında 1/1000000, 10-14 yaş arasında 5/1000000, 15-19 yaş arasında 18/1000000' tır. SEER verilerine göre tiroid nodüllü olgularda tiroid kanseri görülme sıklığı 1/180 $(\% 0,5)$ olarak bildirilmiştir [7]. Yine aynı çalışmada 1973'ten 2004 yılında kadar geçen sürede tiroid kanser insidansında yılda \%1,1 lik artış saptanmıştır [8].

Tiroid nodülleri altta yatan otoimmün tiroid hastalık zemininde gelişebildiği gibi, çevresel faktörlere maruziyet de tiroid nodül ve kanser gelişiminde rol oynayabilmektedir (Tablo 1) [2,9].

\begin{tabular}{|l|}
\hline $\begin{array}{l}\text { Tablo 1. Tiroid nodülü ve kanser gelişiminde rol oynayan } \\
\text { faktörler }\end{array}$ \\
\hline lyot eksikliği \\
\hline Otoimmün tiroidit \\
\hline Aile öyküsü \\
\hline $\begin{array}{l}\text { Radyasyona maruziyet (eksternal radyoterapi ya da radyoak- } \\
\text { tif serpilmeye maruziyet) }\end{array}$ \\
\hline $\begin{array}{l}\text { Tiroglossal kanal kisti (malignansi + konjenital guatr/ } \\
\text { ektopik tiroid dokusu) }\end{array}$ \\
\hline $\begin{array}{l}\text { Genetik sendromlar (Gardner Sendromu, Cowden Send- } \\
\text { romu, Werner Sendromu, MEN2, Carney kompleksi) }\end{array}$ \\
\hline Diğer ailesel geçişli tiroid kanserleri \\
\hline
\end{tabular}

\section{Klinik Değerlendirme}

Tiroid nodüllü olguları değerlendirirken en önemli noktalardan biri olgunun öz ve soy geçmişinde, fizik muayenesinde, laboratuvar sonuçları ya da ultrasonografik değerlendirmesinde malignansiyi düşündüren belirteçleri tespit edebilmektir. $\mathrm{Bu}$ nedenle bu basamakların her birinin üzerinde ayrıntılı ve dikkatli bir şekilde geçilmesi gerekir [10]. Eşlik eden olası tiroid hastalıkları (otoimmün tiroiditler -OT-, tiroid disgenezisi, dishormonegenez), iyot eksikliği, eksternal radyasyon maruziyeti, ailede tiroid kanser öyküsü ve tiroid kanserinin sık görüldüğü genetik sendromlar sorgulanmalıdır [9]. Yine bası semptomları (yutarken takılma hissi, sırt üstü yatarken öksürme ihtiyacı) irdelenmelidir. 120 pediatrik vakanın incelendiği retrospektif bir çalışmada tiroid kanserli olguların çoğunlukla palpe edilebilir lenf nodu ve bası semptomları ile başvurduğu bildirilmiş̧ir [11]. Hipotiroidi ya da hipertiroidinin klinik bulguları (kilo değişimi, yorgunluk, duygusal labilite vs) sorgulanmalı ancak bunların neoplazi açısından prediktif değerinin olmadığı akılda tutulmalıdır [2].

Fizik muayenede nodül boyutları, sertliği, bölgede eritem ya da ISı artışı, hassasiyet, nodülün çevre dokulara fiksasyonu değerlendirilmeli ve eşlik eden olası lenfadenopatiler açısından ayrıntılı bir baş boyun muayenesi yapılmalıdır [10].

\section{Laboratuvar}

sT3, sT4, TSH düzeyleri genellikle hastaların hormonal durumunu değerlendirmek için istense de tiroid kanserli olguların büyük bir kısmının ötroid olduğu, hipertiroidi kliniğinin ön planda olduğu olgularda ise nodül boyutlarının daha büyük olduğu ve bası semptomlarının gözlendiği bildirilmektedir [2,11]. Tiroid antikorlarının değerlendirilmesi ise sitolojik sonuçların yorumlanması ve etiyolojinin aydınlatılması açısından önem arz etmektedir [2]. Veriler sınırlı olmakla birlikte retrospektif bir çalışmada papiller tiroid kanseri (PTK) tanısı alan olguların \%30'unda OT saptandığı bildirilmektedir [13]. Henüz kesinlik kazanmamakla birlikte bir çalışmada TSH düzeyleri normal referans aralığın üst sınırına yaklaşan tiroid nodüllü olgularda malignansi riskinin arttığı vurgulanmıştır [14]. Tanı aşamasında rutinde tiroglobulin düzey ölçümü önerilmemekle birlikte medüller tiroid kanseri (MTK) düşündüren olgularda mutlaka serum kalsitonin düzeyine bakılması gerekir [2]. Serum kalsitonin düzeyi yaşa ve cinsiyete göre değiştiği gibi nöroendokrin hastalıklar, nefropati, sigara ya da alkol kullanımı, OT varlığında yanlış pozitif sonuç verebilmektedir. Bu nedenle yüksek kalsitonin seviyesi saptanan olgularda tekrarlayan ölçümler ya da pentagastrin uyarı testi ile testin spesifitesi artırılması önerilmektedir. Genel kanı ise 100 pg/ml üzerindeki kalsitonin seviyesinin MTK' ı telkin ettiği yönündedir [15].

\section{Radyoloji}

Tiroid ultrasonografi (USG) tiroid nodülünü tarama ve değerlendirmede ilk basamağı oluşturmaktadır. Nodülün boyutunu, şeklini, yapısını vaskülaritesini değerlendirmesinin yanı sıra, klinisyene, boyunda eşlik edebilecek olası lenfadenopatileri değerlendirme şansı da sunmaktadır [12]. Ultrasonografide malignansi ile ilişkilendirilen bulgular Tablo 2 de verilmiştir $[2,16]$. 


\begin{tabular}{|l|}
\hline Tablo 2. Ultrasonografide maligniteyi düşündüren bulgular \\
\hline Soliter solid lezyon \\
\hline Hipoekojenite \\
\hline Heterojen yapı (solid + kistik vb.) \\
\hline Subkapsuler lokalizasyon \\
\hline Düzensiz sınıllar \\
\hline Çevre dokulara bası yapmadan invazif büyüme paterni \\
gösterme \\
\hline Mikrokalsifikasyonlar \\
\hline Doppler değerlendirmede artmış intranodüler kan akımı \\
\hline Eşlik eden şüpheli lenf nodlarının varlığı \\
\hline
\end{tabular}

Corrias ve ark. $>1 \mathrm{~cm}$ çaplı tiroid nodüllü olguları değerlendirdiği bir çalışmada mikrokalsifikasyon varlığı, intranodüler kanlanma artışı ve eşlik eden palpable lenf nodu varlığı malignansi açısından yüksek prediktif değere sahip olarak bulunmuştur [11] (Şekil 1 ve 2).

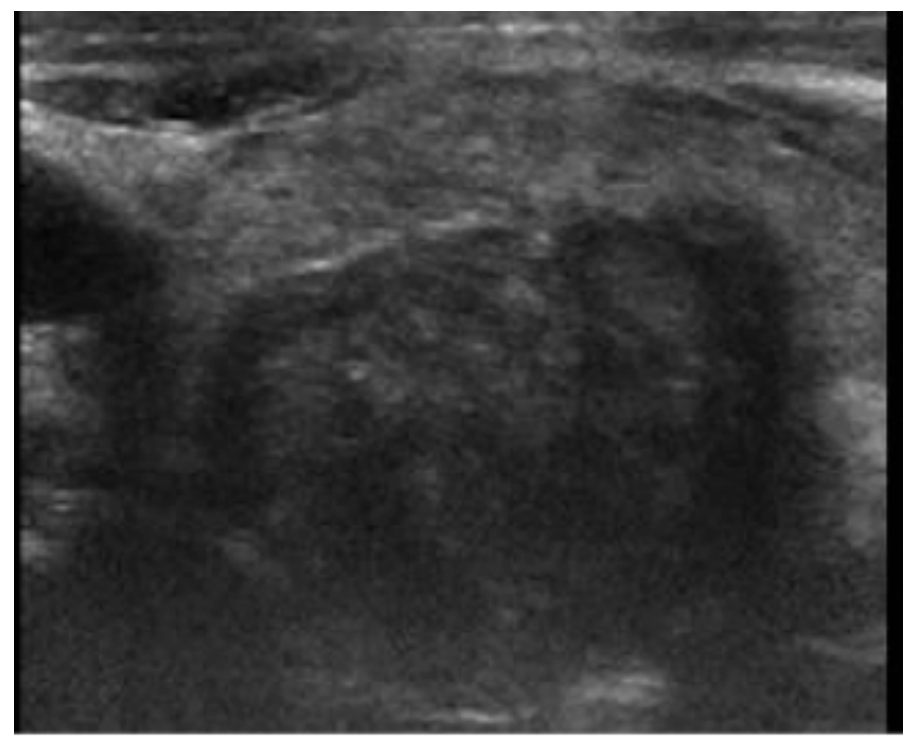

Şekil 1. Sınırları silik ve mikrokalsifikasyonlar içeren tiroid nodülü

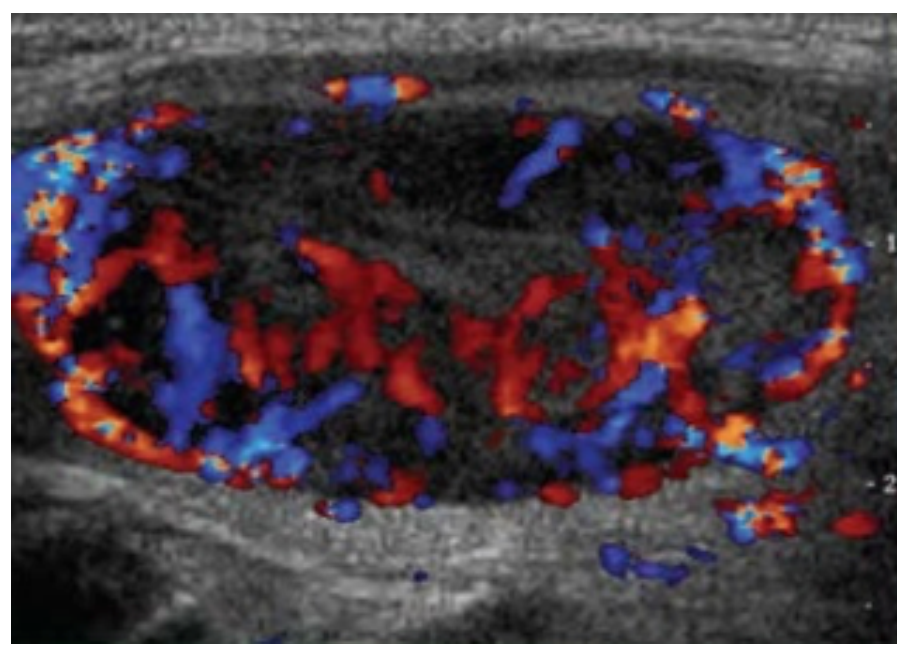

Şekil 2. Doppler ultrasonografide artmış intranduler kan akımı
Ancak USG bulgularının hiç biri tek başına tiroid kanseri saptamada yüksek prediktif değere sahip değildir. Klinik ve/ veya radyolojik olarak malignansiyi düşündüren bulgular Tablo 3' de verilmiştir [2,9].

\begin{tabular}{|l|}
\hline Tablo 3. Tiroid nodülü varlığında malignansiyi düşündüren bulgular \\
\hline$<10$ yaş \\
\hline Kız cinsiyet \\
\hline Çevre dokulara sabitlenmiş sert nodül \\
\hline Nodül boyutlarında hızlı artış \\
\hline Vokal kord paralizi \\
\hline Bölgesel lenf nodlarında genişleme \\
\hline Uzak metastaz varlığı (kemik, akciğer) \\
\hline $\begin{array}{l}\text { Eşlik eden benign tiroid hastalığı varlığı (konjenital hipotiro- } \\
\text { di, otoimmün tiroiditler) }\end{array}$ \\
\hline $\begin{array}{l}\text { Radyasyon maruziyeti (baş-boyun bölgesine ya da tüm } \\
\text { vücuda eksternal radyoterapi veya radyoaktif serpintiye } \\
\text { maruziyet öyküsü }\end{array}$ \\
\hline Ailede tiroid kanseri ya da MEN öyküsü \\
\hline USG de malignansi bulguları \\
\hline Sintigrafide soğuk nodül varlığı \\
\hline $\begin{array}{l}\text { Laboratuvar bulguları (kalsitonin veya CEA yüksekliği, eşlik } \\
\text { eden hiperparatiroidizm, feokromositoma veya ganglion- } \\
\text { öroma varlığı) }\end{array}$ \\
\hline Malign sitoloji \\
\hline
\end{tabular}

Çocukluk çağında önemli bir başka nokta da papiller tiroid kanserinin bu yaş grubunda diffüz infiltratif özellik göstermesidir [17]. Tiroid bezinde diffüz büyüme ile birlikte eşlik eden servikal lenf nodları varlığında USG ile mikrokalsifikasyonların tespiti halinde ince iğne aspirasyon biyopsisi (iïAB) yapılması önerilmektedir [16].

Tiroid sintigrafisinin hiperfonksiyonel nodüllerin tespiti dışında tiroid nodüllü olguların değerlendirmesinde yeri bulunmamaktadır. Ayrıca sintigrafide artmış tutulum olması her zaman malignansiyi dışlamamaktadır $[11,18]$. Hiperfonksiyonel nodüllerde lezyonun çıkarılması planlanıyor ise öncesinde IIIAB önerilmemektedir [16].

\section{İnce İğne Aspirasyon Biyopsisi}

Günümüzde şüpheli olgularda ileri değerlendirme ve kesin tanı için USG eşliğinde $A B$ yapılmaktadır. Çocukluk çağı tiroid nodüllerinin değerlendirme, tedavi ve takip şeması Şekil 3 ' te verilmiştir [16]. American Thyroid Association (ATA) erişkin yaş grubunda yüksek riskli olmadığı sürece $<1 \mathrm{~cm}$ olan nodüllerde $A B$ önermemektedir ancak çocuklarda tiroid volümünün yaşla değişmesi ve nodül boyutunun tek başına prediktif değeri olmaması nedeniyle klinik ve radyolojik bulgular sonucunda ii $A B^{\prime}$ e karar verilmesinin gerektiği vurgulanmaktadır [16]. Özellikle ailede tiroid kanser öyküsü olan, baş-boyun bölgesine radyoterapi alan, nodül boyutlarında hızlı büyüme saptanan, eşlik eden servikal lenfadenopatileri olan ya da radyolojik olarak malignansiyi telkin eden olgularda (mikrokalsifikasyon, 
düzensiz sınırlar, hipoekojenite, artmış vaskülarite, eşlik eden lenf nodu varlığı) $<1 \mathrm{~cm}$ olsa da IİAB önerilmektedir $[4,9,16]$ . Saavedra J ve ark. tiroid nodülü nedeniyle iïAB yapılan 35 olguyu incelediği bir çalışmada tiroid USG'de malign özellik göstermesine karşın IIAB sonucu normal gelen 5 olgunun eksizyonel cerrahi sonrası tiroid kanseri tanısı aldığı bildirilmektedir [19] . Yapılan çalışmalarda IïAB' nin sensivitesi \%80-100, spesifitesi \%65-100 arasında bildirilmektedir [18] IiAB' nin yalancı negatiflik oranı düşük olmakla birlikte büyük lezyonlarda örnekleme hatasının sık olması nedeniyle bu oran artmakta ve bu nedenle büyük lezyonlarda IIAB yerine cerrahi eksizyon önerilmektedir [16,20].

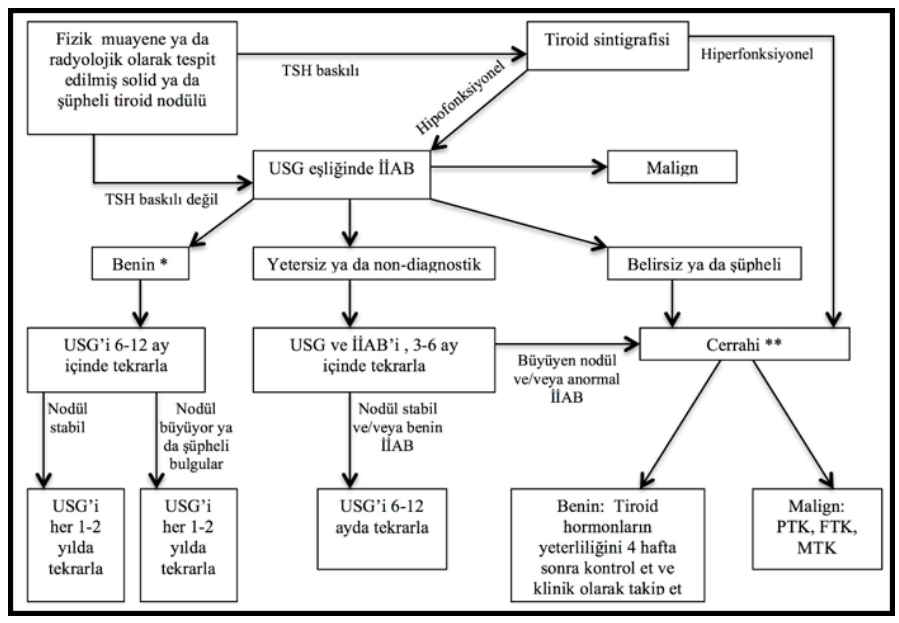

Şekil 3. Tiroid nodüllerinin değerlendirme, tedavi ve takip algoritması. (USG: Ultrasonografi, İAB: İnce iğne aspirasyon biyopsisi, PTK: Papiller tiroid kanseri, FTK: Foliküler tiroid kanseri, MTK: Medüller tiroid kanseri)

*Şüpheli USG ya da klinik bulgular varlığında, bası semptomlarının olması, nodül boyutlarının $>4 \mathrm{~cm}$ olması halinde ve/veya hasta tercihine bağlı olarak cerrahi düşünüle bilinir.

**Subklinik hipertiroidi, otonom nodül olan olgularda cerrahi ertelenebilir ancak PTK açısından şüpheli bulgular varsa iïAB düşünülmelidir (Kaynak 16'dan alınmıştır).

\section{Patoloji}

İAB sonuçlarını değerlendirmede günümüzde yaygın olarak Bethesda evreleme sistemi kullanılmaktadır. Bu sisteme göre sonuçlar; 1) non-diagnostik ya da yetersiz, 2) benign, 3) önemi belirsiz atipi ya da foliküller lezyon (AUS/FLUS), 4) foliküler/Hürtle hücreli neoplasm ya da foliküler/Hürtle hücreli neoplasm için şüpheli, 5) şüpheli malignansi, 6) malignansi olarak raporlanmaktadır [21]. Yetersiz numune gelen olgularda en erken üç ay sonra İAB'nin tekrarlanabileceği, daha erken yapılan girişimlerim atipik selüler özellikler (papiller endotelyal hiperplazi, vasküler proliferasyon, kistik değişiklikler vb) oluşturabileceği belirtilmektedir [22]. Ancak pediatrik populasyonda yapılan sınırlı sayıda çalışmada kesin olmayan sonuçların tüm sonuçların yaklaşık \%35'ini oluşturduğu ve
AUS/FLUS tanısı alan olguların $\% 28$ i, foliküler/Hürtle hücreli neoplazm için şüpheli tanısı alan olguların ise \%58'inde malignansi tespit edildiği bildirilmektedir [23-25]. 2015 yılında yayınlana ATA rehberinde bu olgularda tekrarlayan iiAB'den ziyade lobektomi + istmektomi önerilmektedir [16].

\section{İmmunohistokimya ve Moleküler Tanı}

Yapılan IIAB sonucunda elde edilen materyalde farklı immnünositokimyasal yöntemlerle diferansiye tiroid kanserlerini saptamak amaçlı farklı belirteçler çalışılmıştır (Tablo 4). Ancak bu tanımlanan belirteçlerin hiç biri tek başına tanısal açıdan yeterli değildir. Ayrıca bu belirteçlerin büyük bir kısmının erişkin çalışmaları sonucunda elde edilmiş olması ve pediatrik popülasyonda sınırlı sayıda çalışma bulunması tanısal açıdan kullanımlarını kısıtlamaktadır [9].

\begin{tabular}{|l|}
\hline Tablo 4. Diferansiye tiroid kanserlerini tespitte kullanılan belirteçler \\
\hline E-cadherin \\
\hline b/g cadherin \\
\hline Cytokeratin-19 \\
\hline B4 integrin \\
\hline HMGI(Y) \\
\hline Fra-1 \\
\hline Ets-1 \\
\hline Topoisomerase-II \\
\hline Thyroperossidasis \\
\hline HBME-1 \\
\hline Keratan sülfat \\
\hline Galectin-3 \\
\hline CO44v6 \\
\hline
\end{tabular}

Tiroid kanserli olgularda günümüze kadar tanımlanan bir çok genetik değişim bulunmaktadır. Bunlardan B-Raf protoonkogen mutasyonları ve RET/PTC mutasyonu papiller tiroid kanserde; RET mutasyonu medüller tiroid kanserde; RAS mutasyonu,PAX8/PPARXtranslokasyonutiroidmalignansilerde tanımlanmış olmakla birlikte bu belirteçlerin negatif olması malignansiyi dışlamamaktadır [18]. Günümüzde moleküler tanı adına yapılan çalışmaların büyük bir kısmını erişkin vaka gruplarından elde edilmiştir. Ancak çocuklarda preoperative moleküler çalışmaların cerrahi müdahalenin planlanmasında iyi bir yol gösterici olabileceği öne sürülmüştür [26].

\section{Cerrahi}

IIAB sonucunda benign tiroid nodülü saptanan olgularda nodül boyutlarının büyümesi (erişkinlerde tanımı volümün $\geq \% 50$ artması ya da en az iki çapta $\geq \% 20$ artış olması), bası semptomlarının olması, kozmetik nedenler, hasta tercihine bağlı olarak ya da nodül boyutlarının $>4 \mathrm{~cm}$ olması halinde cerrahi eksizyon önerilmektedir. Tiroid nodülü büyüyen ya da USG de şüpheli görünüm olan olgularda cerrahi öncesi IiAB yapılarak preoperatif evreleme ve cerrahi planlama yapılmalıdır [16]. 
iïAB sonucu malign olan olgularda ise fikse veya geniş volüm yüküne sahip lezyonu olan olgularda bilgisayar tomografi veya manyetik rezonans görüntüleme ile baş ve boyun bölgesinde bulunan şüpheli lenf nodlarının tespit edilmesi, akciğer grafi ile pulmoner metastazların değerlendirilerek iïAB ile cerrahi öncesi evreleme yapılması cerrahi başarı ve komplikasyonların azaltılması açısından önem arz etmektedir $[13,16]$.

Yine semptomatik hipertiroidiye sebep olan sıcak nodül varlığında ya da IIIAB sonucunun şüpheli olması halinde cerrahi önerilmektedir [18].

\section{Takip}

iïAB'nın yalancı negatif değerinin düşük olmasına karşın, büyük lezyonlarda bu oranın artabilmesi, sitolojik değerlendirmenin sensivitesinin farklı çalışmalarda değişkenlik göstermesi nedeniyle bir tiroid nodülünün benign olarak tanımlanmasına karşın belli aralıklarla takibi önerilmektedir [18,20,27]. Özellikle malignansi açısından risk faktörü bulunan (Tablo 3) ya da hızlı büyüme gösteren nodüllerin tekrar IİAB ya da cerrahi eksizyon ile değerlendirilmesi gerekmektedir [27].

Benign tiroid nodüllü olgularda LT4 tedavisine ilişkin literatürde çeliş̧ili sonuçlar bulunmaktadır. Corrias ve ark. çalışmasında benign tiroid nodülü olan olgulara LT4 tedavisi verilerek olguların \%30'unda nodül boyutlarında >\%50 gerileme saptandığı bildirilmiştir [28]. Ancak uzun süreli tedavide LT4 kullanımına bağlı gelişebilecek yan etkiler açısından yeterli veri bulunmamaktadır [29]. 2006 yılında Amerika'dan yayınlanan bir uzlaşı raporunda iyot eksikliği olan bölgelerde küçük tiroid nodüllerinin tedavisinde LT4 verilebileceği ancak nodül boyutlarının büyük olması ya da IïAB sonucunun yetersiz veya şüpheli olması durumunda tedavinin verilmemesi gerektiği vurgulanmıştır [30].

\section{Sonuç}

Çocukluk çağında tiroid nodülleri daha nadir görünmesine karşın malign potansiyelinin yüksek olması ve bu olguların tanı anından genellikle baş boyun bölgesi metastazı ile yakalanması nedeniyle tiroid nodüllü olguların iyi değerlendirilip malignite riski taşıyan olguların IïAB ile incelenmesi, sitoloji sonucu şüpheli olan olgularda ya da malignite saptanan vakalarda ise cerrahi tedavi uygulanması önerilmektedir. Sitoloji sonucu benign olsa bile tiroid nodüllü olgular belirli aralıklarla fizik muayene ve USG ile değerlendirilmeli, malignite düşündüren bulguların tespiti ya da nodül boyutlarında hızlı artış olması halinde tekrar IIAB ya da cerrahi eksizyon yapılmalıdır.

\section{Çıkar çatışması ve Finansman Beyanı}

Bu çalışmada çıkar çatışması ve finansman destek alındığı beyan edilmemiştir.

\section{Kaynaklar}

1. Rallison MI, Dobyns BM, Keating FR Jr, Rall JE, Tyler FH. Thyroid nodularity in children. JAMA 1975; 233: 1069.

2. Niedziella M. Pathogenesis, diagnosis and management of thyroid nodules in children. Endocr Relat Cancer 2006; 13: 427-53.

3. Dinauer CA, Breuer C, Rivkees SA. Differantiated thyroid cancer in children: diagnosis and management. Curr Opin Oncol 2008; 20:59-65.

4. Gupta A, Ly S, Castroneves LA, et al. A standardized assessment of thyroid nodules in children confirms higher cancer prevalence than in adults. J Clin Endocrinol Metab 2013; 98: 3238.

5. Dean DS, Gharib H. Epidemiology of thyroid nodules. Best Pract Res Clin Endocrinol Metab 2008; 22: 901-11.

6. Halac I, Zimmmerman D. Thyroid nodules and cancers in children. Endocrinol Metab Clin North Am 2005; 34: 725-44.

7. Hogan AR, Zhuge $Y$, Perez EA, Koniaris LG, Lew Jl, Sola JE. Pediatric thyroid carcinoma: incidence and outcomes in 1753 patients. J Surg Res 2009; 156-67.

8. Hung W. Solitary thyroid nodules in 93 children and adolescents. A 35 years experience. Horm Res 1999; 52: 15.

9. Corrias A, Mussa A. Thyroid nodules in pedistrics: which ones can be left alone, which ones must be investigated, when and how. J Clin Res Pediatr Endocrinol 2013; 5: 57-69.

10. Önder A, Aycan Z. Approach to thyroid nodules in children and adolescents. Turk J of Pediatr 2014; 56: 219-25.

11. Corrias A, Mussa A, Baronio F, et al. Study Group for Thyroid diseases of Italian Society for Pediatric Endocrinology and Diabetology (SIEDP/ISPED). Diagnostic features of thyroid nodules in pediatrics. Arch Pediatr Adolesc Med 2010; 164: 714-9.

12. Goldfarb M, Gondek SS, Sanchez Y, Lew Jl. Clinic-based ultrasound can predict malignancy in pediatric thyroid nodules. Thyroid 2012; 22: 827-31.

13. Corrias A, Cassio A, Weber G, et al. Thyroid nodules and cancer in children and adolescents affected by autoimmune thyroiditis. Arch Pediatr Adolesc Med 2008; 162: 526-31.

14. McLeod DS, Watters KF, Carpenter AD, Ladenson PW, Cooper DS, Ding EL. Thyrotropin and thyroid cancer diagnosis: a systematic review and dose-response metaanalysis. J Clin Endocrinol Metab 2012; 97: 2682-92.

15. Elisei R. Rotine calcitonin measurement in the evaluation of thyroid nodules. Best Pract Res Clin Endocrinol Metab. 2008; 22: 941-53.

16. Francis GL, Waguespack SG, Bauer AJ, et al. Management Guidelines for Children with Thyroid Nodules and Differentiated Thyroid Cancer. The American Thyroid Association Guidelines Task Force on Pediatric Thyroid Cancer. Thyroid 2015; 25: 716-59. 
17. Halac I, Zimmerman D. Thyroid tumors in children. In Liftshitz F. (eds) Pediatric Endocrinology, 5th edition, Informa Healthcare USA Inc. New York, 2007: 455-73.

18. Guille JT, Opoku-Boateng A, Thibeault SL, Chen S. Evaluation and Management of Pediatric Thyroid nodüle. The Oncologist 2015; 20: 19-27.

19. Saavedra J, Deladoey J, Saint-Vil D, et al. Is ultrasonography useful in predicting thyroid cancer in children with thyroid nodules and apparently benign cytopathologic features? Horm Res Paediatr 2011; 75: 269-75.

20. Wharry LI, McCoy KL, Stang MT, et al. Thyroid nodules $(>/=4 \mathrm{~cm})$ : can ultrasound and cytology reliably exclude cancer? World J Surg 2014: 38; 614-21.

21. Chibas ES, Ali SZ. The Bethesda System for Reporting Thyroid Cytopathology. Thyroid 2009; 19: 1159-65.

22. Baloch ZW, LiVolsi VA Post fine-needle aspiration histologic alterations of thyroid revisited. Am J Clin Pathol 1999; 112: 311-6.

23. Smith M, Pantanowitz L, Khalbuss WE, Benkovich VA, Monaco SE. Indeterminate pediatric thyroid fine needle aspirations: a study of 68 cases. Acta Cytol 2013; 57: 341-8.

24. Monaco SE, Pantanowitz L, Khalbuss WE, et al. Cytomorphological and molecular genetic findings in pediatric fine-needle aspiration. Cancer Cyto-Pathol 2012; 120: 342-50.
25. Stevens C, Lee JK, Sadatsafavi M, Blair GK. Pediatric thyroid fineneedle aspiration cytology: a meta-analysis. J Pediatr 2009; 44: 2184-91.

26. Buryk MA, Monaco SE, Witchel SF, et al. Preoperative cytology with molecular analysis to help guide surgery for pediatric thyroid nodules. Int J Pediatr Otolaryngol 2013; 77: 1697-1700.

27. De Luca F, Tommaso A, Alessi L, et al. Thyroid nodules in childhood: indications for biopsy and surgery. Italian Journal of Pediatrics 2014; 19: 40-8.

28. Corrias A, Mussa A, Wasniewska M, et al. Levothyroxine treatment in pediatric benign nodules. Horm Res Paediatr 2011; 75: 246-51.

29. Yousef A, Clark J, Suhail AR. Thyroxine Suppression Therapy For Benign, Non-Functioning Solitary Thyroid Nodules: A QualityEffects Meta-Analysis. Clin Med Res. 2010; 8: 150-8.

30. AACE/AME Task Force on Thyroid nodules, American Association of Clinical Endocrinologists and Associazone Medici Endocrinologi Medical Guidelines for clinical practice for the diagnosis and management of thyroid nodules. Endocr Pract 2006; 12: 63-102. 